\title{
Late diagnosis of MDMA-related severe hyponatremia
}

\author{
J ulia Chia-Yu Chang ${ }^{1}$, Jin Ger ${ }^{2}$, Chen-Chang Yang ${ }^{2-4}$ \\ 1. Department of Emergency Medicine, Taipei Veterans General Hospital, Taipei, Taiwan. 2. Division of Clinical Toxicology \\ \& Occupational Medicine, Department of Medicine, Taipei Veterans General Hospital, Taipei, Taiwan. 3. Institute of \\ Environmental \& Occupational Health Sciences, School of Medicine, National Yang-Ming University, Taipei, Taiwan. 4. \\ Department of Environmental \& Occupational Medicine, Faculty of Medicine, School of Medicine, National Yang-Ming \\ University, Taipei, Taiwan.
}

Correspondence: Chen-Chang Yang. Address: Division of Clinical Toxicology \& Occupational Medicine, Department of Medicine, Taipei Veterans General Hospital, 322 Shih-Pai Road Section 2, Taipei 11217, Taiwan. Email: ccyang@vghtpe.gov.tw

Received: April 21, 2014

Accepted: May 19, 2014

Online Published: May 27, 2014

DOI : $10.5430 /$ crim.v1n2p153

URL: http://dx.doi.org/10.5430/crim.v1n2p153

\section{Abstract}

Introduction: 3, 4-methylenedioxymethamphetamine (MDMA) is a popular psychoactive amphetamine derivative with the potential to induce life-threatening hyponatremia. The absence of exposure history and typical toxidromes however make the prompt diagnosis of MDMA-induced hyponatremic coma difficult and easily overlooked.

Case Report: A 24-year-old female presented to the emergency department with an altered mental status. Physical examinations, laboratory workup and brain imaging study were remarkable for severe hyponatremia (serum sodium 116 $\mathrm{mmol} / \mathrm{L}$ ) and diffuse brain edema only. Her family denied that she had used any illicit drugs. The diagnosis of MDMA-related hyponatremic coma was not made until six days later when toxicologic screen confirmed the presence of high concentration of MDMA (7,767 ng/ml) in the patient's urine.

Conclusion: Our case demonstrates the difficulty in the correct diagnosis of MDMA-induced hyponatremic coma in the absence of MDMA exposure history and typical sympathomimetic effects. A high index of suspicion and prompt toxicological screen are thus important in the diagnosis of MDMA-related severe hypontremia.

\section{Keywords}

Coma, Ecstasy, Hyponatremia, MDMA

\section{I ntroduction}

3, 4-methylenedioxymethamphetamine (MDMA, ecstasy) is a psychoactive amphetamine derivative that is popular among young adults and commonly consumed in night clubs. MDMA is regarded by recreational drug users as harmless with minimal side effects and without habit-forming hazards. However, numerous reports have testified to the direct physical and mental adverse effects, and even mortality associated with MDMA ingestion ${ }^{[1]}$. MDMA has a chemical structure similar to endogenous catecholamines (i.e. epinephrine and norepinephrine); thus it can stimulate the central nervous system via the release of endogenous catecholamines, resulting in tachycardia, hypertension and dilated pupils ${ }^{[1]}$. MDMA is known to induce life-threatening hyponatremia ${ }^{[1-3]}$. Although the diagnosis of MDMA-related hyponatremia is 
generally not difficult in the presence of relevant exposure history and/or typical sympathomimetic manifestations, timely diagnosis can be challenging in patients devoid of the above-noted clinical information.

\section{Case report}

A 24-year-old previously healthy female presented to the emergency department (ED) due to altered mental status. On the night before arrival at the ED, she partied with friends at a karaoke bar. She was found to suffer nausea and vomiting, followed by loss of consciousness in the early morning. She was first dispatched to a local hospital where hyponatremia, coma (Glasgow Coma Scale E2V2M4), and slight mydriasis with bilateral pupil size of $5 \mathrm{~mm}$ were noted. Initial vital signs were as follows: temperature $36.1^{\circ} \mathrm{C}$ and blood pressure of $138 / 90 \mathrm{mmHg}$. She was then transferred to our service for further management.

Upon arrival, her vital signs were as follows: blood pressure 93/75mmHg, pulse rate 93/min, respiratory rate 18/min, and body temperature $35.8^{\circ} \mathrm{C}$. Glasgow Coma Scale was E1V1M4 and bilateral pupil size was $2 \mathrm{~mm}$ with preserved light reflex. Other physical examinations were unremarkable. Pertinent laboratory data were as follows: serum sodium 116 $\mathrm{mmol} / \mathrm{L}$ (reference range $135-147 \mathrm{mmol} / \mathrm{L}$ ), potassium $4.3 \mathrm{mmol} / \mathrm{L}(3.5-4.5 \mathrm{mmol} / \mathrm{L})$, creatinine $0.7 \mathrm{mg} / \mathrm{dL}(0.5-1.5$ $\mathrm{mg} / \mathrm{dL})$, free calcium $0.94 \mathrm{mmol} / \mathrm{L}(1.13-1.31 \mathrm{mmo} / \mathrm{L})$, uric acid $1.2 \mathrm{mg} / \mathrm{dL}$ (1.8-6.2 mg/dL), serum osmolality 231 mosm $/ \mathrm{kg}$ (280-292 mosm $/ \mathrm{kg})$, urine osmolality $344 \mathrm{mosm} / \mathrm{kg}$, urine chloride $114 \mathrm{mmol} / \mathrm{L}$ and urine sodium $76 \mathrm{mmol} / \mathrm{L}$. Arterial blood gas analysis revealed $\mathrm{pH}$ 7.365, $\mathrm{pCO}_{2} 30.2 \mathrm{mmHg}, \mathrm{pO}_{2} 109.2 \mathrm{mmHg}$, and $\mathrm{HCO}_{3} 16.9 \mathrm{mmo} / \mathrm{L}$ under 3L/min oxygen supplement. Adrenal and thyroid function tests were both within normal limits.

Despite the lack of documented head trauma or seizures, computed tomography of brain was performed to rule out possible intracranial lesions leading to the patient's comatose status (e.g. subarachnoid or intracerebral hemorrhage), which revealed the presence of diffuse brain swelling (see Figure 1). She was then admitted to the intensive care unit where intravenous 3\% saline was administered for the treatment of severe euvolemic hyponatremia. Urine sodium concentration and urine osmolality after saline therapy were $160 \mathrm{mmol} / \mathrm{L}$ and $379 \mathrm{mosm} / \mathrm{kg}$, respectively.

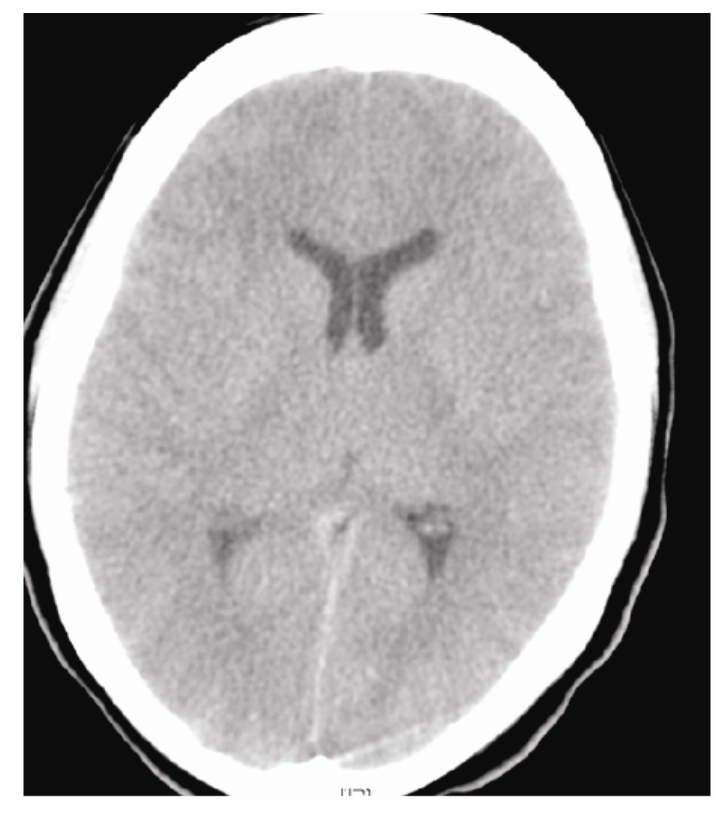

Figure 1. Brain computed tomography in a 24-year-old female with MDMA-induced hyponatremic coma revealed diffuse swelling of brain parenchyma. 
Although her serum sodium level was once as low as $110 \mathrm{mmol} / \mathrm{L}$, it gradually increased to $133 \mathrm{mmol} / \mathrm{L}$ by the end of day 2. The patient was fully awake on day 3 with serum sodium levels ranging between 133 and $137 \mathrm{mmol} / \mathrm{L}$. Drug/toxicant related syndrome of inappropriate antidiuretic hormone secretion (SIADH) was suspected; however the patient denied taking any recreational drugs or toxicants.

Urine toxicologic screen performed upon arrival at the ED by employing gas chromatography/mass spectrometry analysis was positive for MDMA $(7,767 \mathrm{ng} / \mathrm{ml})$ and its metabolite MDA $(375 \mathrm{ng} / \mathrm{ml})$ on day 6 . It was with much reluctance that the patient finally admitted to having ingested one tablet of MDMA at the party where she also drank $1,200 \mathrm{ml}$ of bottled water prior to loss of consciousness. The patient was discharged uneventfully.

\section{Discussion}

Hyponatremia, defined as a serum sodium concentration less than $135 \mathrm{mmol} / \mathrm{L}$, is multi-factorial, thus rendering differential diagnosis difficult. Hyponatremia may be a result of depletion in effective circulating volume such as true volume depletion, heart failure and cirrhosis. Moreover, hormonal diseases such as adrenal insufficiency and hypothyroidism can be associated with low serum sodium. Athletes participating in competitive sports are also at high risk for hyponatremia, as a result of excess free water drinking and sweating ${ }^{[4]}$. SIADH is a disorder of impaired water excretion caused by an inability to suppress the secretion of antidiuretic hormone (ADH), and may be a result of CNS disturbances, malignancies, drugs, HIV infection or surgery ${ }^{[5]}$. All of the above-mentioned potential causes of hyponatremia deserve attention in the differential diagnosis.

In our patient, history-taking and detailed physical examinations revealed neither history of fluid loss (e.g. vomiting, diarrhea, diuretic therapy and strenuous exercise) nor signs of fluid overload that indicates the diagnosis of heart failure, cirrhosis and renal failure. Moreover, a measured serum osmolality of $231 \mathrm{mosm} / \mathrm{kg}$ ruled out the possibility of non-hypotonic hyponatremia ${ }^{[6]}$, such as hyperglycemia, azotemia and alcohol poisoning related hyponatremia. The presence of high urine osmolality (344 mosm $/ \mathrm{kg}$ ) further excluded the diagnosis of primary polydipsia and low solute intake that were commonly associated with a urine osmolality of less than $100 \mathrm{mosm} / \mathrm{kg}{ }^{[7]}$. The finding of high urine sodium (75 mmol/L) also suggested that effective volume depletion (e.g. hypovolemia, heart failure, and cirrhosis) was unlikely to be present in the patient ${ }^{[8]}$. Drug-induced SIADH was finally diagnosed by taking into account the patient's overall clinical features and excluding all of the above-mentioned alternative diagnoses ${ }^{[5,6,8,9]}$.

Many drugs can induce hyponatremia via various mechanisms, such as the alteration of sodium and water homeostasis, increased production of $\mathrm{ADH}$, potentiation of the effect of $\mathrm{ADH}$ and reset osmostat ${ }^{[3]}$. Among drug-induced hyponatremia, SIADH is not uncommonly seen and has been linked to numerous drugs such as antidepressants, antipsychotic, antiepileptics, anticancer agents, and narcotics ${ }^{[3,5]}$. Notably, MDMA has also been associated with the development of SIADH ${ }^{[1,2,5,10]}$.

MDMA, a psychoactive amphetamine with structural similarity to serotonin, possesses more potent serotonergic properties and generates positive feelings and mood elevation to recreational users ${ }^{[11]}$. Side effects of MDMA include dry mouth, increased thirst, restlessness, palpitation, dizziness, drowsiness, confusion and anxiety. ${ }^{[10]}$ MDMA-induced hyperthermia in the acutely poisoned patients was also well-documented ${ }^{[12,13]}$ along with rhabdomyolysis ${ }^{[14]}$, hepatic failure ${ }^{[15]}$, disseminated intravascular coagulation (DIC) ${ }^{[14]}$, and death ${ }^{[2]}$. Users of MDMA learn to increase their oral water intake as a preventive measure for hyperthermia, resulting in potentially severe cases of MDMA-associated hyponatremia ${ }^{[1]}$.

Symptoms related to hyponatremia generally occur within hours after MDMA ingestion. Patients might present with altered mental status and cerebral edema ${ }^{[1,14]}$. Symptomatic hyponatremia with a serum sodium level less than 130 $\mathrm{mmol} / \mathrm{L}$ is one of the serious complications associated with MDMA ${ }^{[5]}$. MDMA-induced dipsogenic effect ${ }^{[16]}$, ready 
availability of drinks and excessive intake of free water all directly contribute to the development of hyponatremia. Moreover, the parent compound of MDMA and its major and more potent metabolite, 4-hydroxy-3methoxymethamphetamine (HMMA), both can lead to the release of arginine vasopressin (AVP), which further aggravates symptomatic hyponatremia ${ }^{[17]}$. Animal studies showed that MDMA and its metabolites led to serotonin secretion in the central nervous system ${ }^{[18]}$, resulting in the release of AVP from the neurohypophysis ${ }^{[19]}$. A rapid decrease in serum sodium levels then results in an osmotic shift of free water from plasma into the cells, predisposing MDMA poisoned patients to pulmonary edema, cerebral edema, seizures, coma, brain stem herniation, and even death ${ }^{[20]}$. Among previous case reports of MDMA-induced hyponatremia, many were women aged between 15 and 30 years who ingested a single dose of ecstasy ${ }^{[21]}$. Moreover, the incidence of hyponatremia was markedly higher in women (27.3\%) as compared to that in men $(3.0 \%)^{[22]}$.

Although the diagnosis of MDMA-related hyponatremia is generally not difficult, timely diagnosis can be challenging in patients without relevant exposure history and/or typical sympathomimetic manifestations, as evidenced in this case report. Patients with MDMA-related hyponatremia may present in a state of profound coma rendering history-taking impossible. Moreover, most MDMA abusers are reluctant in revealing their habit of illicit drug use, making it difficult in acquiring accurate exposure information even among those who are awake. The diagnosis is further complicated when patients suffering from MDMA-induced coma do not present with typical features of sympathomimetic toxidrome.

Our patient presented to the ED in a comatose status without manifesting mydriasis, diaphoresis, elevated blood pressure, tachycardia, or tachypnea. The only telltale sign was transient mydriasis that was documented at a local hospital. If prompt toxicologic screen had not been performed in this patient, the diagnosis of MDMA-related hyponatremic coma would have been overlooked. Therefore, emergency physicians should harbor a high index of suspicion of MDMA abuse among young patients who present to the ED with undetermined cause of hyponatremia. Appropriate toxicologic screen should then be conducted to confirm the diagnosis.

\section{References}

[1] Traub SJ, Hoffman RJ, Nelson LS. The “Ecstasy” hangover: Hyponatremia due to 3,4-methylenedioxymethamphetamine. Bull N Y Acad Med. 2002; 79: 549-555. http://dx.doi.org/10.1093/jurban/79.4.549

[2] Parr MJ, Low HM, Botterill P. Hyponatraemia and death after “ecstasy” ingestion. Med J Aust. 1997; 166: $136-137$.

[3] Liamis G, Milionis H, Elisaf M. A review of drug-induced hyponatremia. Am J Kidney Dis. 2008; 52: 144-153. http://dx.doi.org/10.1053/j.ajkd.2008.03.004

[4] Hew-Butler T, Jordaan E, Stuempfle KJ, Speedy DB, Siegel AJ, Nokaes TD, et al. Osmotic and nonosmotic regulation of arginine vasopressin during prolonged endurance exercise. J Clin Endocrinol Metab. 2008; 93: 2072-2078. http://dx.doi.org/10.1210/jc.2007-2336

[5] Ellison DH, Berl T. Clinical practice. The syndrome of inappropriate antidiuresis. N Engl J Med. 2007; 356: $2064-2072$. http://dx.doi.org/10.1056/NEJMcp066837

[6] Fazekas AS, Funk G-C, Klobassa DS, Ruther H, Ziegler I, Zander R, et al. Evaluation of 36 formulas for calculating plasma osmolality. Intensive Care Med. 2012; 39: 302-308. http://dx.doi.org/10.1007/s00134-012-2691-0

[7] Schwartz WB, Bennett W, Curelop S, Bartter FC. A syndrome of renal sodium loss and hyponatremia probably resulting from inappropriate secretion of antidiuretic hormone. Am J Med. 1957; 23: 529-542. http://dx.doi.org/10.1016/0002-9343(57)90224-3

[8] Chung HM, Kluge R, Schrier RW, Anderson RJ. Clinical assessment of extracellular fluid volume in hyponatremia. Am J Med. 1987; 83: 905-908. http://dx.doi.org/10.1016/0002-9343(87)90649-8

[9] Graber M, Corish D. The electrolytes in hyponatremia. Am J Kidney Dis 1991; 18: 527-545.

[10] Campbell GA, Rosner MH. The agony of ecstasy: MDMA (3, 4-Methylenedioxymethamphetamine) and the kidney. Clin J Am Soc Nephrol. 2008; 3: 1852-1860. http://dx.doi.org/10.2215/CJN.02080508

[11] Curran HV, Travill RA. Mood and cognitive effects of 3, 4-methylenedioxymethamphetamine (MDMA, “ecstasy”): week-end “high” followed by mid-week low. Addiction. 1997; 92: 821-831. http://dx.doi.org/10.1111/j.1360-0443.1997.tb02951.x

[12] Hermle L, Spitzer M, Borchardt D, Kovar KA, Gouzoulis E. Psychological effects of MDE in normal subjects. Are entactogens a new class of psychoactive agents? Neuropsychopharmacology. 1993; 8: 171-176. http://dx.doi.org/10.1038/npp.1993.19 
[13] Henry JA, Jeffreys KJ, Dawling S. Toxicity and deaths from 3, 4-methylenedioxy-methamphetamine (“ecstasy”). Lancet. 1992; 340: 384-387. http://dx.doi.org/10.1016/0140-6736(92)91469-O

[14] Screaton GR, Singer M, Cairns HS, Thrasher A, Sarner M, Cohen SL. Hyperpyrexia and rhabdomyolysis after MDMA (“ecstasy”) abuse. Lancet. 1992; 339: 677-678. http://dx.doi.org/10.1016/0140-6736(92)90834-P

[15] Andreu V, Mas A, Bruguera M, Salmeron JM, Moreno V, Nogue S, Rodes J. Ecstasy: a common cause of severe acute hepatotoxicity. J Hepatol. 1998; 29: 394-397. http://dx.doi.org/10.1016/S0168-8278(98)80056-1

[16] Simmler LD, Hysek CM, Liechti ME. Sex differences in the effects of MDMA (ecstasy) on plasma copeptin in healthy subjets. J Clin Endocrinol metab. 2011; 96: 2844-2850. http://dx.doi.org/10.1210/jc.2011-1143

[17] Fallon JK, Shah D, Kicman AT, Hutt AJ, Henry JA, CowanDA, et al. Addiction of MDMA (ecstasy) and its metabolites on arginine vasopressin release. Ann N Y Acad Sci. 2002; 965: 399-409. http://dx.doi.org/10.1111/j.1749-6632.2002.tb04181.x

[18] Hall AP, Henry JA: Acute toxic effects of ecstasy (MDMA) and related compounds: Overview of pathophysiology and clinical management. Br J Anaesth. 2006; 96: 678-685. http://dx.doi.org/10.1093/bja/ael078

[19] Iovino M, Steardo L. Effects of substances influencing brain serotonergic transmission on plasma vasopressin levels in the rat. Eur J Pharmacol. 1985; 113: 99-103. http://dx.doi.org/10.1016/0014-2999(85)90347-4

[20] Peroutka SJ. Incidence of recreational use of 4-methylenedioxymethamphetamine (MDMA, ecstasy) on an undergraduate campus. N Engl J Med. 1987; 317: 1542-1543. http://dx.doi.org/10.1056/NEJM198712103172419

[21] Brown C, Osterloh J. Multiple severe complications from recreational ingestion of MDMA (ecstasy). JAMA. 1987; 258: 780-781. http://dx.doi.org/10.1001/jama.1987.03400060056021

[22] Dijken GD., Blom RE. High incidence of mild hyponatremia in females using ecstasy at a rave party. Nephro Dial Transplant. 2013; 28: 2277-2283. http://dx.doi.org/10.1093/ndt/gft023 